\title{
Pemilihan Dosen Penguji Skripsi Menggunakan Metode ARAS, COPRAS dan WASPAS
}

\author{
Juniar Hutagalung ${ }^{[1]^{*}}$, Mentari Tri Indah $\mathrm{R}^{[2]}$ \\ Program Studi Sistem Informasi, STMIK Triguna Dharma ${ }^{[1]}$ \\ Jalan AH. Nasution No. 73 Medan, Indonesia ${ }^{[1]}$ \\ Program Studi Manajemen Dakwah, STAIN Bengkalis ${ }^{[2]}$ \\ Jalan Lembaga Senggoro, Riau, Indonesia ${ }^{[2]}$ \\ juniarhutagalung991@gmail.com ${ }^{[1]}$, mentari.tri@gmail.com ${ }^{[2]}$
}

\begin{abstract}
ARAS is a method based on the principle that alternatives must have the largest ratio to produce an optimal solution. COPRAS is a method based on the ratio of favorable criteria and adverse criteria. WASPAS is a method that can reduce errors or optimize estimates for the selection of the highest and lowest values. ARAS, COPRAS AND WASPAS methods are the methods used for ranking. Determination of thesis examiner lecturers in this study using the ARAS, COPRAS, and WASPAS methods with 5 criteria: tenure, functional, competence, education, and study assignments and there are 20 alternative data. The appointment of thesis examiners at STMIK Triguna Dharma is currently carried out directly and manually and sometimes overrides the number of students to be tested so that the number is less balanced for each lecturer. It is still found that less than optimal decisions when appointing lecturers are not in accordance with the theme of student thesis so that the value of the quality of scientific work decreases. For that, we need a system that is useful in determining prospective examiners, to match the competence of prospective examiners, and not too many students will be tested so that they are more focused. Comparison of the methods in this study by ranking to obtain an optimal and objective alternative begins by determining the weight of each criterion, the ranking results are sorted from the highest value so that the selection of examiners is easy to determine and as a recommendation tool for decision making. To get the best choice, the ARAS method uses the highest utility value (Ki), the COPRAS method is based on the highest quantitative utility assessment value (Ui) and the WASPAS method uses the highest preference value $(\mathrm{Qi})$ to get the best choice. The best alternative with the ARAS method produces $(\mathrm{A6}=\mathbf{0 . 9 3 8 5})$, then A5, A19, A3, A11, A14, A16, A18, A10, A4, A17, A9 deserve to be recommended. The COPRAS method yielded $(\mathrm{A} 6=100)$ and the WASPAS method yielded $(\mathrm{A6} 6 \mathbf{0 . 7 0 8 3})$.
\end{abstract}

\section{Keywords-ARAS, COPRAS, DSS, Examiner, WASPAS}

Abstrak - ARAS merupakan metode yang didasarkan pada prinsip intuitif bahwa alternatif harus memiliki rasio terbesar untuk menghasilkan solusi yang optimal. COPRAS adalah metode yang berdasarkan pada rasio kriteria yang menguntungkan dan kriteria yang merugikan. WASPAS merupakan metode yang dapat mengurangi kesalahan-kesalahan atau mengoptimalkan dalam penaksiran untuk pemilihan nilai tertinggi dan terendah. Metode ARAS, COPRAS DAN WASPAS merupakan metode yang digunakan untuk perangkingan. Penentuan dosen penguji skripsi dalam penelitian ini menggunakan metode ARAS, COPRAS dan WASPAS dengan 5 kriteria: Masa kerja, fungsional, kompetensi, pendidikan dan tugas belajar serta ada 20 data alternatif. Penunjukan dosen penguji skripsi di STMIK Triguna Dharma, saat ini dilakukan masih secara langsung dan manual serta jumlah mahasiswa yang akan diuji sehingga kurang seimbang jumlahnya untuk setiap dosen. Masih ada ditemukan keputusan yang kurang optimal saat penunjukan dosen yang tidak sesuai dengan tema skripsi mahasiswa sehingga nilai kualitas karya ilmiah menurun. Untuk itu diperlukan sistem yang berguna dalam penentuan calon dosen penguji, agar sesuai dengan kompetensi calon dosen penguji dan tidak terlalu banyak jumlah mahasiswa yang akan diuji agar lebih fokus. Ketiga metode ini adalah bagian dari Multi Criteria Decision Making (MCDM), yaitu metode pengambilan keputusan untuk menetapkan alternatif terbaik dari sejumlah alternatif berdasarkan beberapa kriteria tertentu. Perbandingan metode dalam penelitian ini dengan melakukan perangkingan supaya diperoleh alternatif secara optimal dan objektif diawali dengan penentuan bobot dari setiap kriteria, hasil ranking diurutkan dari nilai yang tertinggi agar pemilihan dosen penguji mudah ditentukan dan sebagai alat rekomendasi bagi pihak pengambil keputusan. Untuk mendapatkan pilihan terbaik metode ARAS menggunakan nilai utilitas $(\mathrm{Ki})$ tertinggi, metode COPRAS didasarkan pada skor penilaian utilitas quantitatif (Ui) tertinggi dan metode WASPAS menggunakan nilai preferensi (Qi) tertinggi untuk mendapatkan pilihan terbaik. Alternatif terbaik dengan metode ARAS menghasilkan $(\mathbf{A 6}=0,9385)$ selanjutnya $A 5$, A19, A3, A11, A14, A16, A18, A10, A4, A17, A9 layak untuk direkomendasi. Metode COPRAS menghasilkan (A6=100) dan metode WASPAS menghasilkan $(\mathrm{A6}=\mathbf{0 , 7 0 8 3})$.

\section{Kata Kunci-ARAS, COPRAS, DSS,Penguji, WASPAS}

\section{PENDAHULUAN}

Salah satu syarat untuk lulus dari program sarjana adalah setiap mahasiswa harus membuat skripsi, selanjutnya dilakukan ujian skripsi melalui seminar proposal, seminar hasil dan sidang 
skripsi. Dalam membuat dan melaksanakan ujian skripsi, penunjukan dosen penguji skripsi oleh tim Prodi STMIK Triguna Dharma saat ini dilakukan secara langsung dan manual dengan penentuan dan mempertimbangkan masa kerja, fungsional, kompetensi, pendidikan dan tugas belajar.

Namun penunjukan tersebut terkadang mengesampingkan jumlah mahasiswa yang akan dibanding dan diuji akibatnya kurang seimbang dengan jumlah quota setiap dosen. Jumlah mahasiswa yang banyak dan judul skripsi yang beragam, menjadi pertimbangan dalam menentukan dosen penguji yang kompeten sesuai dengan judul skripsi para mahasiswa. Masih ada ketidaksesuaian kompetensi dosen dengan tema skripsi yang diajukan oleh para mahasiswa. Selain itu membutuhkan waktu yang lama untuk menyelesaikan banyaknya antrian dalam penunjukan dosen penguji skripsi. Tim Prodi selektif dalam memutuskan dosen penguji skripsi yang sesuai, ada banyak faktor yang harus diperhitungkan matang-matang.

Permasalahan-permasalahan tersebut dapat diatasi dengan membangun sistem pendukung keputusan sesuai kriteriakriteria sehingga bermanfaat untuk pemilihan dosen penguji skripsi, dengan tujuan agar kualitas skripsi mahasiswa dapat ditingkatkan sesuai dengan kompetensi calon dosen penguji skripsi. Dosen yang dipilih tidak terlalu banyak menguji mahasiswa agar lebih fokus dan kualitas dari karya ilmiah mahasiswa lebih optimal. Disamping itu proses penentuan dosen penguji skripsi dapat dilakukan dengan mudah, tepat dan cepat.

Sistem pendukung keputusan dengan komparasi metode ARAS, COPRAS dan WASPAS dalam menentukan dosen penguji skripsi diharapkan dapat membantu tim Prodi untuk menyelesaikan masalah dalam penelitian ini secara objektif berdasarkan multi kriteria yang ditentukan. Penerapan metode ARAS, COPRAS dan WASPAS lebih sesuai dengan kasus ini karena terdapatnya pemecahan unsur kriteria dan pembobotan pada masing-masing kriteria, selanjutnya menghasilkan perangkingan dan alternatif yang terpilih layak sebagai dosen penguji skripsi, dengan tiga metode tersebut dapat menyaring dan menentukan dosen penguji skripsi.

Terdapat beberapa referensi penelitian sebagai dasar untuk mengangkat judul penelitian ini. Adanya kombinasi beberapa metode dalam sistem pendukung keputusan, diantaranya penentuan dosen penguji dan pembimbing tugas akhir menggunakan FMADM SAW sesuai spesifikasi dosen penguji dan pembimbing [1]. Perhitungan dilakukan dengan menggunakan metode AHP, dimana kriteria untuk pemilihan dosen pembimbing dan penguji tugas akhir dapat ditentukan secara dinamis dan disesuaikan dengan kebutuhan [2]. Metode TF-IDF dan VSM digunakan untuk menentukan dosen penguji berdasarkan kompetensi, dengan 59 data judul dapat merekomendasikan tiga dosen penguji skripsi, dengan syarat minimal satu orang memiliki kompetensi yang sama dengan topik skripsi [3].

Perbandingan tiga metode yaitu WASPAS, COPRAS dan EDAS dalam menentukan judul skripsi, dimana algoritma boyer moore yang lebih tepat untuk proses penyaringan pesan terbaik dari judul skripsi para mahasiswa [4]. Metode WP, SAW dan WASPAS, diterapkan untuk menentukan penerimaan beasiswa PMDK [5]. Penerapan metode MOORA, SWARA dan WASPAS dalam pemulihan ponsel bekas. Keputusan alternatif dengan peringkat terbaik adalah alternatif $\mathrm{C}$ dan alternatif $\mathrm{G}$ menempati urutan kedua saat $\lambda=0,5$ sedangkan alternatif D sebagai yang terburuk untuk melakukan pembalikan operasi logistik dalam rantai pasokan terintegrasi pada perusahaan telepon seluler [6].

Pengambilan keputusan dalam menangani informasi saling berhubungan atau kontra diktif dengan kriteria dan lingkungan. Hal ini membantu praktisi dan akademisi untuk mengadopsi teknik utilitas MCDM baru seperti SWARA dan WASPAS dengan cara yang berbeda baik dari aplikasi maupun melalui literatur [7]. Metode SWARA dan ARAS digunakan untuk mengevaluasi dan menyeleksi calon personel atau karyawan yang kompetensinya dibutuhkan untuk posisi tertentu dalam perusahaan [8]. Metode FAHP dan WASPAS digunakan untuk melakukan evaluasi dan pemilihan layanan cloud. Penilaian bobot dilakukan melalui FAHP dan WASPAS digunakan untuk menentukan peringkat layanan cloud [9]. Perbandingan metode ARAS dan COPRAS dimana metode ARAS dan COPRAS memiliki rangking yang sama untuk perusahaan GAFRA karena yang paling konsisten [10].

Penerapan metode COPRAS dan fuzzy digunakan untuk mengevaluasi kinerja dari strategi pemeliharaan produktif secara optimal [11]. Teknik pengambilan keputusan multikriteria terintegrasi berdasarkan Fuzzy-AHP dan WASPAS digunakan untuk mengidentifikasi infrastruktur informasi penting yang terkait dengan jenis potensi ancaman terhadap keamanan nasional [12]. Penilaian pemasok akan dilakukan dengan membandingkan metode MOORA dan COPRAS. Metode COPRAS dipilih karena langkah perhitungannya lebih sederhana dan rata-rata perbedaan nilai rangking akhir cukup kecil. Penelitian ini juga menghasilkan kriteria pemilihan vendor kunci untuk perusahaan ABC yang bergerak di bidang pertambangan di Indonesia [13]. Penelitian ini mengkombinasikan metode SWARA dan metode WASPAS guna mengevaluasi dan memberi peringkat tantangan kritis intervensi Digital Technologies (DTs) untuk mengendalikan wabah COVID-19. Prosedur SWARA diterapkan untuk menganalisis dan menilai tantangan intervensi DTs selama wabah COVID-19, dan pendekatan WASPAS digunakan untuk memberi perangkingan [14].

\section{Metode Penelitian}

\section{A. Additive Ratio Assessment (ARAS)}

Pada metode ARAS dapat menentukan efisiensi relatif kompleks dari alternatif yang layak dan sebanding dengan relatif dari nilai dan bobot kriteria utama yang dipertimbangkan dalam suatu proyek melalui nilai fungsi utilitas [15]. Melalui metode ARAS setiap alternatif dinilai sesuai dengan kriteria yang telah ditetapkan lalu diperoleh perangkingan dengan membandingkan antar alternatif agar mendapat hasil yang ideal dan terbaik sehingga dapat memberikan solusi mitra kerja mana yang terbaik [16]. Metode ARAS digunakan untuk mengukur kinerja manajemen supply chain pada perusahaan kecil dan menengah melalui kriteria barang yang berkualitas, tingkat kerusakan, pengembalian dan pengiriman tepat waktu 
memperoleh prioritas tertinggi [17]. Metode ARAS adalah metode yang efektif dan mudah digunakan untuk menyelesaikan banyak masalah MCDM di berbagai bidang seperti pemilihan kepala akuntan peringkat keuangan institusi dan masalah yang terkait dengan konstruksi [8]. Metode ARAS dapat membandingkan pada alternatif fungsi utilitas dengan nilai dari fungsi optimum sebagai baseline [18]. Pada metode ARAS, setelah dinormalisasikan datanya dan bobot setiap kriteria dikalikan selanjutnya dijumlahkan normalisasi matriks terbobot untuk penentuan nilai Si. Kemudian hitung tingkat utilitas Ki untuk menentukan nilai peringkat alternatif [19].

Metode ARAS memiliki nilai korelasi tertinggi karena hasil perangkingan metode ARAS mendekati sempurna, memiliki fungsi nilai optimum atau nilai baseline akan menghasilkan nilai korelasi dasar yang lebih baik. Hal ini terbukti dari hasil nilai korelasi dasar yang dihasilkan [20]. Tahapan-tahapan algoritma dalam metode ARAS sebagai berikut :

1. Pembentukan decicion making matrix, seperti rumus 1 .

$$
\mathrm{x}=\left[\begin{array}{ccccc}
\mathrm{x}_{01} & \cdots & \mathrm{x}_{0 \mathrm{j}} & \cdots & \mathrm{x}_{0 \mathrm{n}} \\
\vdots & \ddots & \vdots & \ddots & \vdots \\
\mathrm{x}_{\mathrm{ij}} & \cdots & \mathrm{x}_{\mathrm{ij}} & \cdots & \mathrm{x}_{\mathrm{nj}} \\
\vdots & \ddots & \vdots & \ddots & \vdots \\
\mathrm{x}_{\mathrm{n} 1} & \cdots & \mathrm{x}_{\mathrm{mj}} & \cdots & \mathrm{x}_{\mathrm{mn}}
\end{array}\right] \mathrm{i}=\mathrm{m}, 0 ; \mathrm{j}=1, \mathrm{n}
$$

2. Penormalisasian decision making matrix, seperti rumus 2 .

$$
\mathrm{x}=\left[\begin{array}{ccccc}
\overline{\mathrm{x}}_{01} & \cdots & \overline{\mathrm{x}}_{0 \mathrm{j}} & \cdots & \overline{\mathrm{x}}_{0 \mathrm{n}} \\
\vdots & \ddots & \vdots & \ddots & \vdots \\
\overline{\mathrm{x}}_{\mathrm{ij}} & \cdots & \overline{\mathrm{x}}_{\mathrm{ij}} & \cdots & \overline{\mathrm{x}}_{\mathrm{nj}} \\
\vdots & \ddots & \vdots & \ddots & \vdots \\
\overline{\mathrm{x}}_{\mathrm{n} 1} & \cdots & \overline{\mathrm{x}}_{\mathrm{mj}} & \cdots & \overline{\mathrm{x}}_{\mathrm{mn}}
\end{array}\right] \mathrm{i}=\overline{0, \mathrm{~m}} ; \mathrm{j}=\overline{1, \mathrm{n}}
$$

3. Normalisasi bila kriteria bernilai maksimum, seperti rumus 3.

$$
\overline{\mathrm{x}}_{\mathrm{ij}}=\frac{\mathrm{x}_{\mathrm{ij}}}{\sum_{\mathrm{i}=0}^{\mathrm{m}} \mathrm{x}_{\mathrm{ij}}}
$$

Normalisasi bila kriteria bernilai minimum, seperti rumus 4.

$$
x_{i j}=\frac{1}{x^{*}{ }_{i j}} ; \bar{x}_{i j}=\frac{x_{i j}}{\sum_{i=0}^{m} x_{i j}}
$$

4. Penentuan bobot matriks, seperti rumus 5 dan 6 .

$$
\hat{\mathrm{x}}=\left[\begin{array}{ccccc}
\sum_{\mathrm{j}=1}^{\mathrm{n}} \mathrm{w}_{\mathrm{j}}=1 \\
\hat{\mathrm{x}}_{01} & \cdots & \hat{\mathrm{x}}_{0 \mathrm{j}} & \cdots & \hat{\mathrm{x}}_{0 \mathrm{n}} \\
\vdots & \ddots & \vdots & \ddots & \vdots \\
\hat{\mathrm{x}}_{\mathrm{ij}} & \cdots & \hat{\mathrm{x}}_{\mathrm{ij}} & \cdots & \hat{\mathrm{x}}_{\mathrm{nj}} \\
\vdots & \ddots & \vdots & \ddots & \vdots \\
\hat{\mathrm{x}}_{\mathrm{n} 1} & \cdots & \hat{\mathrm{x}}_{\mathrm{mj}} & \cdots & \hat{\mathrm{x}}_{\mathrm{mn}}
\end{array}\right] \mathrm{i}=\overline{0, \mathrm{~m}} ; \mathrm{j}=\overline{1, \mathrm{n}} \ldots \ldots
$$

5. Menentukan nilai dari fungsi optimum, seperti rumus 7.

$$
\mathrm{S}_{\mathrm{I}}=\sum_{\mathrm{j}=1}^{\mathrm{n}} \hat{\mathrm{x}}_{\mathrm{ij}} ; \mathrm{i}=\overline{0, \mathrm{~m}}
$$

6. Menentukan nilai peringkat, seperti rumus 8 .

$$
K_{i}=\frac{s_{i}}{s_{0}} ; i=\overline{0, m}
$$

\section{B. Complex Proportional Assessment (COPRAS)}

Metode COPRAS dapat menunjukkan waktu kalkulasi yang lebih singkat, sangat mendasar, transparansi yang baik, dan kemungkinan tinggi dalam strategi pemahaman grafis dibandingkan dengan metode yang lain dengan mempertimbangkan ketergantungan faktor prioritas dan tingkat utilitas objek dan atribut yang berlawanan [21].

Metode COPRAS ini dapat mengevaluasi dan menilai mana kriteria yang menguntungkan dan tidak menguntungkan serta lebih unggul dari metode lainnya karena dapat menghitung tingkat utilitas alternatif yang menunjukkan sejauh mana alternatif yang diambil sebagai perbandingan [22]. Metode COPRAS digunakan untuk kemungkinan linguistik diatur di bawah domain neutrosofik [23]. Mempresentasikan pendekatan pengambilan keputusan berdasarkan metode COPRAS dengan informasi fuzzy [24]. Metode COPRAS digunakan untuk menilai penyakit obstruktif kronik berdasarkan linguistik fuzzy [25].

Metode fuzzy-COPRAS digunakan untuk menangani keadaan di mana para pengambil keputusan ragu-ragu menilai alternatif, variabel, dan lain-lain dalam pemilihan kualitas layanan [26]. Metode COPRAS diterapkan untuk melakukan analisis dan pemilihan alternatif sesuai dengan fungsi utilitas dan nilai-nilai dari atribut dinyatakan dalam interval untuk mengefisiensikan dan mengoptimalkan ketepatan dalam mengambil keputusan [27].

Langkah-langkah metode COPRAS sebagai berikut:

1. Membuat matriks keputusan, seperti rumus 9 .

$$
D=\left(\begin{array}{ccccc}
A_{1} & X_{11} & X_{12} & X_{13} & X_{1 n} \\
A_{2} & X_{21} & X_{22} & X_{23} & X_{2 n} \\
A_{3} & X_{31} & X_{32} & X_{33} & X_{3 n} \\
A_{4} & X_{41} & X_{42} & X_{43} & X_{4 n} \\
A_{m} & X_{m 1} & X_{m 2} & X_{m 3} & X_{m n}
\end{array}\right)
$$

2. Normalisasi matriks, seperti rumus 10 .

$$
X_{i j}=\frac{X_{i j}}{\sum_{1=1}^{m} X_{i j}}
$$

3.Menentukan matriks keputusan berbobot yang ternormalisasi, seperti rumus 11 .

$$
D^{\prime}=d_{i j}=X_{i j} \times W_{j}
$$

4. Perhitungan memaksimalkan dan meminimalkan indeks, seperti rumus 12 dan 13 .

$$
\begin{aligned}
S_{+i} & =\sum_{j=1}^{n} d_{+i j} \\
S_{-i} & =\sum_{j=1}^{n} d_{-i j}
\end{aligned}
$$

5. Tentukan signifikansi alternatif berdasarkan penentuan alternatif positif $S_{+i}$ dan alternatif negatif $S_{-i}$.

6. Tentukan signifikansi relatif atau prioritas relatif $\left(Q_{i}\right)$, seperti rumus 14

$$
Q_{i}=S_{+i}+\frac{S_{-i \min } \sum_{i=1}^{m} S_{-i}}{S_{-i} \sum_{i=1}^{m}\left(S_{-m} / S_{-i}\right)}
$$




$$
=S_{+i}+\frac{S_{-i \min } \sum_{i=1}^{m} S_{-i}}{S_{-i} \sum_{i=1}^{m}\left(S_{-m} / S_{-i}\right)}(i=1,2, \ldots, m)
$$

7. Hitung utilitas kuantitatif (Ui), seperti rumus 15.

$$
U_{i=}\left[\frac{Q_{i}}{Q_{\max }}\right] \times 100 \%
$$

\section{Weighted Aggregates Sum Product Assessment (WASPAS)}

Metode yang digunakan dalam sistem pendukung keputusan, diantaranya adalah WASPAS [28]. WASPAS merupakan metode yang menggabungkan 2 kriteria optimalitas, kriteria pertama dari optimalitas adalah penjumlahan tertimbang dari normalisasi nilai kinerja yang mirip dengan metode SAW dan kriteria kedua mirip dengan metode WP [29]. Penerapan metode WASPAS untuk memilih lingkungan dalam ruangan yang optimal, dengan mengakses 6 apartemen dan menunjukkan bahwa apartemen ke-2 memiliki ruangan yang terbaik di antara yang dibandingkan [30]. Tujuan utama dari manajemen rantai pasokan hijau adalah untuk meminimalkan dampak ekologis yang merusak di semua aktivitas dan fase rantai pasokan. Mengevaluasi pemasok dan memilih pemasok terbaik berdasarkan kriteria lingkungan dengan menerapkan metode fuzzy- WASPAS [31]. WASPAS merupakan bagian dari Weighted-Sum Model (WSM) dan Weighted-Product Model (WPM). WSM digunakan untuk menentukan skor dan jumlah bobot dari keseluruhan alternatif dan WPM untuk menghindari alternatif dengan nilai atribut yang buruk [32], [33].

Tahapan metode WASPAS [34], yaitu :

1. Pembentukan Decicion Making Matrix, seperti rumus 16.

$$
x=\left(\begin{array}{ccccc}
x_{i j} & \cdots & x_{i j} & \cdots & x_{n j} \\
\vdots & \ddots & \vdots & \ddots & \vdots \\
x_{n 1} & \cdots & x_{m j} & \cdots & x_{m n}
\end{array}\right) i=m, 0 ; j=1, n
$$

2. Penormalisasian Decision Making Matrix, seperti rumus 17 dan 18.

$$
\begin{aligned}
& \text { Kiteria Benefit } \\
& X_{i j}=\frac{X_{i j}}{\max X_{i j}}
\end{aligned}
$$

\section{Kriteria Cost}

$$
X_{i j}=\frac{\min X_{i j}}{X_{i j}}
$$

3. Matrik keputusan ternormalisasi, seperti rumus 19.

$$
x=\left(\begin{array}{ccccc}
x_{i j} & \cdots & x_{i j} & \cdots & x_{n j} \\
\vdots & \ddots & \vdots & \ddots & \vdots \\
x_{n 1} & \ldots & x_{m j} & \cdots & x_{m n}
\end{array}\right) i=\bar{m}, 0 ; j=1, \bar{n} \ldots . .
$$

4. Menentukan bobot matriks yang sudah dinormalisasi, seperti rumus 20 .

$$
\sum_{j=1}^{n} w_{j}=1
$$

$$
Q_{i}=0,5 \sum_{j=1}^{n} x_{i j}+0,5 \prod_{j=1}^{n}\left(x_{i j}^{w j}\right)
$$

\section{HASIL DAN PEMBAHASAN}

Berdasarkan sumber referensi yang telah disebutkan sebelumnya, penulis menyelesaikan masalah pengambilan keputusan dalam pemilihan dosen penguji skripsi dengan melakukan komparasi metode ARAS, COPRAS dan WASPAS.

\section{A. Data Penelitian}

Penentuan dosen penguji skripsi perlu adanya kriteria yang nantinya setiap alternatif akan dibandingkan berdasarkan kriteria-kriteria tersebut. Berikut adalah kriteria yang digunakan untuk menentukan dosen penguji skripsi, seperti terlihat pada tabel 1. Benefit digunakan jika nilai terbesar adalah terbaik.

TABEL 1. TABEL KRITERIA

\begin{tabular}{|l|l|l|l|}
\hline Kriteria & Keterangan & Jenis & Bobot \\
\hline C1 & Masa Kerja & Benefit & 0,2 \\
\hline C2 & Fungsional & Benefit & 0,15 \\
\hline C3 & Kompetensi & Benefit & 0,35 \\
\hline C4 & Pendidikan & Benefit & 0,2 \\
\hline C5 & Tugas Belajar & Benefit & 0,1 \\
\hline
\end{tabular}

Berikut ini nilai dari masing-masing kriteria. a. Masa Kerja (C1), dapat dilihat pada tabel 2.

TABEL 2. TABEL MASA KERJA

\begin{tabular}{|c|c|}
\hline Masa Kerja & Nilai \\
\hline 1 Tahun & 1 \\
\hline 2 Tahun & 2 \\
\hline 3 Tahun & 3 \\
\hline 4 Tahun & 4 \\
\hline$\geq 5$ Tahun & 5 \\
\hline
\end{tabular}

b. Fungsional (C2), dapat dilihat pada tabel 3 .

TABEL 3. TABEL FUNGSIONAL

\begin{tabular}{|l|c|}
\hline Jabatan Fungsional & Nilai \\
\hline Tenaga Pengajar (TP) & 1 \\
\hline Asisten Ahli (AA) & 2 \\
\hline Lektor (L) & 3 \\
\hline Lektor Kepala (LK) & 4 \\
\hline Guru Besar (GB) & 5 \\
\hline
\end{tabular}

c. Kompetensi (C3), dapat dilihat pada tabel 4.

TABEL 4. TABEL KOMPETENSI

\begin{tabular}{|l|l|c|}
\hline \multicolumn{1}{|c|}{ Kompetensi } & Kategori & Nilai \\
\hline NonKomputer (NK) & Tidak Memenuhi & 1 \\
\hline Komputer $(\mathrm{K})$ & Memenuhi & 5 \\
\hline
\end{tabular}

d. Jenjang Pendidikan (C4), dapat dilihat pada tabel 5.

TABEL 5. TABEL JENJANG PENDIDIKAN

\begin{tabular}{|c|c|}
\hline Jenjang Pendidikan & Nilai \\
\hline S1 & 1 \\
\hline S2 & 2 \\
\hline S3 & 3 \\
\hline
\end{tabular}

5. Menentukan nilai Qi, seperti rumus 21. 
e. Tugas Belajar (C5), dapat dilihat pada tabel 6 TABEL 6. TABEL TUGAS BELAJAR

\begin{tabular}{|l|c|}
\hline Tugas Belajar & Nilai \\
\hline Sedang Tugas Belajar & 1 \\
\hline Tidak Tugas Belajar & 2 \\
\hline
\end{tabular}

Data calon dosen penguji dengan sampel data 20 orang dari 75 orang dosen di STMIK Triguna Dharma. Tabel 7 merupakan sampel data calon dosen penguji skripsi (Alternatif).

TABEL 7. TABEL ALTERNATIF

\begin{tabular}{|c|c|c|c|c|c|c|}
\hline $\begin{array}{l}\text { Alter } \\
\text { natif }\end{array}$ & $\begin{array}{l}\text { Inisial } \\
\text { Nama }\end{array}$ & $\begin{array}{c}\text { Masa } \\
\text { Kerja } \\
\text { (C1) }\end{array}$ & $\begin{array}{c}\text { Fung } \\
\text { sional } \\
\text { (C2) }\end{array}$ & $\begin{array}{c}\text { Kompe } \\
\text { tensi } \\
\text { (C3) }\end{array}$ & $\begin{array}{l}\text { Pendi } \\
\text { dikan } \\
(\mathrm{C} 4)\end{array}$ & $\begin{array}{c}\text { Tugas } \\
\text { Belajar } \\
\text { (C5) }\end{array}$ \\
\hline A1 & $\mathrm{AF}$ & 3 & TP & $\mathrm{K}$ & S2 & Tidak \\
\hline $\mathrm{A} 2$ & AM & 2 & $\mathrm{TP}$ & $\mathrm{K}$ & $\mathrm{S} 2$ & Tidak \\
\hline A3 & AFB & $>5$ & $\mathrm{~L}$ & $\mathrm{~K}$ & S2 & Tidak \\
\hline A4 & AP & 4 & AA & K & S2 & Tidak \\
\hline A5 & $\mathrm{AH}$ & 4 & $\mathrm{~L}$ & K & S3 & Tidak \\
\hline A6 & DN & $>5$ & AA & $\mathrm{K}$ & S3 & Tidak \\
\hline A7 & $\mathrm{AC}$ & $>5$ & LK & NK & S3 & Tidak \\
\hline A8 & ELF & $>5$ & AA & NK & S2 & Tidak \\
\hline A9 & ER & 3 & AA & $\mathrm{K}$ & $\mathrm{S} 2$ & Tidak \\
\hline A10 & FS & 3 & $\mathrm{~L}$ & $\mathrm{~K}$ & S2 & Tidak \\
\hline A11 & FR & 4 & AA & K & $\mathrm{S} 2$ & $\mathrm{Ya}$ \\
\hline A12 & SM & 4 & AA & NK & S2 & Tidak \\
\hline A13 & IM & $>5$ & $\mathrm{~L}$ & NK & S2 & Tidak \\
\hline A14 & JP & 4 & $\mathrm{~L}$ & $\mathrm{~K}$ & S2 & Tidak \\
\hline A15 & $\mathrm{JH}$ & 4 & $\mathrm{~L}$ & NK & S2 & Tidak \\
\hline A16 & $\mathrm{KE}$ & 5 & AA & $\mathrm{K}$ & S2 & Tidak \\
\hline A17 & MS & 3 & $\mathrm{TP}$ & $\mathrm{K}$ & S2 & $\mathrm{Ya}$ \\
\hline A18 & MI & 3 & AA & $\mathrm{K}$ & S2 & $\mathrm{Ya}$ \\
\hline A19 & PS & 4 & LK & K & S2 & Tidak \\
\hline A20 & RI & 4 & $\mathrm{TP}$ & $\mathrm{K}$ & S2 & Tidak \\
\hline
\end{tabular}

\section{B. Penerapan Metode ARAS}

Langkah-langkah yang dilakukan dalam pengolahan data pada metode ARAS :

1. Membuat Matriks Keputusan

Nilai optimum dari setiap kriteria berada pada baris paling atas (A0), seperti tabel 8 .

TABEL 8. TABEL MATRIKS KEPUTUSAN

\begin{tabular}{|c|c|c|c|c|c|c|}
\hline $\begin{array}{c}\text { Alter } \\
\text { natif }\end{array}$ & $\begin{array}{c}\text { Inisial } \\
\text { Nama }\end{array}$ & $\begin{array}{c}\text { Masa } \\
\text { Kerja } \\
(\text { C1 }) \\
\text { Max }\end{array}$ & $\begin{array}{c}\text { Fung } \\
\text { sional } \\
(\text { C2) } \\
\text { Max }\end{array}$ & $\begin{array}{c}\text { Kompe } \\
\text { tensi } \\
(\text { C3) } \\
\text { Max }\end{array}$ & $\begin{array}{c}\text { Pendi } \\
\text { dikan } \\
(\mathbf{C 4}) \\
\text { Max }\end{array}$ & $\begin{array}{c}\text { Tugas } \\
\text { Belajar } \\
(\text { C5) } \\
\text { Min }\end{array}$ \\
\hline A0 & - & 5 & 4 & 5 & 3 & 1 \\
\hline
\end{tabular}

\begin{tabular}{|c|c|c|c|c|c|c|}
\hline A1 & AF & 3 & 1 & 5 & 2 & 2 \\
\hline A2 & AM & 2 & 1 & 5 & 2 & 2 \\
\hline A3 & AFB & 5 & 3 & 5 & 2 & 2 \\
\hline A4 & AP & 4 & 2 & 5 & 2 & 2 \\
\hline A5 & AH & 4 & 4 & 5 & 3 & 2 \\
\hline A6 & DN & 5 & 4 & 5 & 3 & 2 \\
\hline A7 & AC & 5 & 3 & 1 & 3 & 2 \\
\hline A8 & ELF & 5 & 2 & 1 & 2 & 2 \\
\hline A9 & ER & 3 & 2 & 5 & 2 & 2 \\
\hline A10 & FS & 3 & 3 & 5 & 2 & 2 \\
\hline A11 & FR & 4 & 2 & 5 & 2 & 1 \\
\hline A12 & SM & 4 & 2 & 1 & 2 & 2 \\
\hline A13 & IM & 5 & 3 & 1 & 2 & 2 \\
\hline A14 & JP & 4 & 3 & 5 & 2 & 2 \\
\hline A15 & JH & 4 & 3 & 1 & 2 & 2 \\
\hline A16 & KE & 5 & 2 & 5 & 2 & 2 \\
\hline A17 & MS & 3 & 1 & 5 & 2 & 1 \\
\hline A18 & MI & 3 & 2 & 5 & 2 & 1 \\
\hline A19 & PS & 4 & 4 & 5 & 2 & 2 \\
\hline A20 & RI & 4 & 1 & 5 & 2 & 2 \\
\hline Jumlah & 84 & 52 & 85 & 46 & 38 \\
\hline
\end{tabular}

\section{Normalisasi Matriks Keputusan}

Langkah selanjutnya adalah menjumlahkan kolom matriks penilaian calon dosen penguji (alternatif), Kemudian matriks dinormalisasikan dengan membagi nilai dengan jumlah kolom dari kriteria. Berikut adalah hasil dari penormalisasian matriks keputusan dapat dilihat pada tabel 9 . TABEL 9. TABEL NORMALISASI MATRIKS KEPUTUSAN

\begin{tabular}{|c|c|c|c|c|c|c|}
\hline $\begin{array}{c}\text { Alter } \\
\text { natif }\end{array}$ & $\begin{array}{c}\text { Masa } \\
\text { Kerja } \\
\text { (C1) } \\
\text { Max }\end{array}$ & $\begin{array}{c}\text { Fung } \\
\text { sional } \\
\text { (C2) } \\
\text { Max }\end{array}$ & $\begin{array}{c}\text { Kompe } \\
\text { tensi } \\
\text { Max } \\
\text { Max }\end{array}$ & $\begin{array}{c}\text { Pendi } \\
\text { dikan } \\
\text { (C4) } \\
\text { Max }\end{array}$ & \multicolumn{2}{|c|}{$\begin{array}{c}\text { Tugas Belajar } \\
\text { (C5) } \\
\text { Min }\end{array}$} \\
\hline A0 & 0,0595 & 0,0769 & 0,0588 & 0,0652 & 1,0000 & 0,0800 \\
\hline A1 & 0,0357 & 0,0192 & 0,0588 & 0,0435 & 0,5000 & 0,0400 \\
\hline A2 & 0,0238 & 0,0192 & 0,0588 & 0,0435 & 0,5000 & 0,0400 \\
\hline A3 & 0,0595 & 0,0577 & 0,0588 & 0,0435 & 0,5000 & 0,0400 \\
\hline A4 & 0,0476 & 0,0385 & 0,0588 & 0,0435 & 0,5000 & 0,0400 \\
\hline A5 & 0,0476 & 0,0769 & 0,0588 & 0,0652 & 0,5000 & 0,0400 \\
\hline A6 & 0,0595 & 0,0769 & 0,0588 & 0,0652 & 0,5000 & 0,0400 \\
\hline
\end{tabular}




\begin{tabular}{|c|c|c|c|c|c|c|}
\hline A7 & 0,0595 & 0,0577 & 0,0118 & 0,0652 & 0,5000 & 0,0400 \\
\hline A8 & 0,0595 & 0,0385 & 0,0118 & 0,0435 & 0,5000 & 0,0400 \\
\hline A9 & 0,0357 & 0,0385 & 0,0588 & 0,0435 & 0,5000 & 0,0400 \\
\hline A10 & 0,0357 & 0,0577 & 0,0588 & 0,0435 & 0,5000 & 0,0400 \\
\hline A11 & 0,0476 & 0,0385 & 0,0588 & 0,0435 & 1,0000 & 0,0800 \\
\hline A12 & 0,0476 & 0,0385 & 0,0118 & 0,0435 & 0,5000 & 0,0400 \\
\hline A13 & 0,0595 & 0,0577 & 0,0118 & 0,0435 & 0,5000 & 0,0400 \\
\hline A14 & 0,0476 & 0,0577 & 0,0588 & 0,0435 & 0,5000 & 0,0400 \\
\hline A15 & 0,0476 & 0,0577 & 0,0118 & 0,0435 & 0,5000 & 0,0400 \\
\hline A16 & 0,0595 & 0,0385 & 0,0588 & 0,0435 & 0,5000 & 0,0400 \\
\hline A17 & 0,0357 & 0,0192 & 0,0588 & 0,0435 & 1,0000 & 0,0800 \\
\hline A18 & 0,0357 & 0,0385 & 0,0588 & 0,0435 & 1,0000 & 0,0800 \\
\hline A19 & 0,0476 & 0,0769 & 0,0588 & 0,0435 & 0,5000 & 0,0400 \\
\hline A20 & 0,0476 & 0,0192 & 0,0588 & 0,0435 & 0,5000 & 0,0400 \\
\hline Total & & & & & 12,5000 & \\
\hline
\end{tabular}

\begin{tabular}{|l|c|c|c|c|c|c|}
\hline A16 & KE & 0,0119 & 0,0058 & 0,0206 & 0,0087 & 0,0040 \\
\hline A17 & MS & 0,0071 & 0,0029 & 0,0206 & 0,0087 & 0,0080 \\
\hline A18 & MI & 0,0071 & 0,0058 & 0,0206 & 0,0087 & 0,0080 \\
\hline A19 & PS & 0,0095 & 0,0115 & 0,0206 & 0,0087 & 0,0040 \\
\hline A20 & RI & 0,0095 & 0,0029 & 0,0206 & 0,0087 & 0,0040 \\
\hline
\end{tabular}

4. Menentukan Nilai Fungsi Optimalisasi (Si)

Menentukan nilai fungsi optimalisasi $(\mathrm{Si})$, nilai indeks keseluruhan setiap alternatif dihitung dengan cara menjumlah elemen matriks keputusan ternormalisasi terbobot pada setiap alternatif. Berikut adalah hasil dari perhitungan nilai fungsi optimalisasi dapat dilihat pada tabel 11.

TABEL 11. TABEL HASIL NILAI OPTIMALISASI (SI)

\begin{tabular}{|c|c|c|c|c|c|c|}
\hline $\begin{array}{c}\text { Alter } \\
\text { natif }\end{array}$ & $\begin{array}{c}\text { Masa } \\
\text { Kerja } \\
\text { (C1) }\end{array}$ & $\begin{array}{c}\text { Fung } \\
\text { sional } \\
\text { (C2) }\end{array}$ & $\begin{array}{c}\text { Kompe } \\
\text { tensi } \\
\text { (C3) }\end{array}$ & $\begin{array}{c}\text { Pendi } \\
\text { dikan } \\
\text { (C4) }\end{array}$ & $\begin{array}{c}\text { Tugas } \\
\text { Belajar }\end{array}$ & Si \\
\hline A0 & 0,0119 & 0,0115 & 0,0206 & 0,0130 & 0,0080 & 0,0651 \\
\hline A1 & 0,0071 & 0,0029 & 0,0206 & 0,0087 & 0,0040 & 0,0433 \\
\hline A2 & 0,0048 & 0,0029 & 0,0206 & 0,0087 & 0,0040 & 0,0409 \\
\hline A3 & 0,0119 & 0,0087 & 0,0206 & 0,0087 & 0,0040 & 0,0538 \\
\hline A4 & 0,0095 & 0,0058 & 0,0206 & 0,0087 & 0,0040 & 0,0486 \\
\hline A5 & 0,0095 & 0,0115 & 0,0206 & 0,0130 & 0,0040 & 0,0587 \\
\hline A6 & 0,0119 & 0,0115 & 0,0206 & 0,0130 & 0,0040 & 0,0611 \\
\hline A7 & 0,0119 & 0,0087 & 0,0041 & 0,0130 & 0,0040 & 0,0417 \\
\hline A8 & 0,0119 & 0,0058 & 0,0041 & 0,0087 & 0,0040 & 0,0345 \\
\hline A9 & 0,0071 & 0,0058 & 0,0206 & 0,0087 & 0,0040 & 0,0462 \\
\hline A10 & 0,0071 & 0,0087 & 0,0206 & 0,0087 & 0,0040 & 0,0491 \\
\hline A11 & 0,0095 & 0,0058 & 0,0206 & 0,0087 & 0,0080 & 0,0526 \\
\hline A12 & 0,0095 & 0,0058 & 0,0041 & 0,0087 & 0,0040 & 0,0321 \\
\hline A13 & 0,0119 & 0,0087 & 0,0041 & 0,0087 & 0,0040 & 0,0374 \\
\hline A14 & 0,0095 & 0,0087 & 0,0206 & 0,0087 & 0,0040 & 0,0515 \\
\hline A15 & 0,0095 & 0,0087 & 0,0041 & 0,0087 & 0,0040 & 0,0350 \\
\hline A16 & 0,0119 & 0,0058 & 0,0206 & 0,0087 & 0,0040 & 0,0510 \\
\hline A17 & 0,0071 & 0,0029 & 0,0206 & 0,0087 & 0,0080 & 0,0473 \\
\hline A18 & 0,0071 & 0,0058 & 0,0206 & 0,0087 & 0,0080 & 0,0502 \\
\hline A19 & 0,0095 & 0,0115 & 0,0206 & 0,0087 & 0,0040 & 0,0543 \\
\hline A20 & 0,0095 & 0,0029 & 0,0206 & 0,0087 & 0,0040 & 0,0457 \\
\hline
\end{tabular}

5. Menentukan Peringkat

Menentukan tingkatan peringkat tertinggi dari alternatif Utility Degree $(\mathrm{Ki})$, dengan cara membagi nilai alternatif

3. Menentukan Bobot Matriks

Caranya elemen matrik keputusan ternormalisasi dikalikan dengan elemen bobot kriteria. Berikut adalah hasil dari perhitungan pembobotan matriks dapat dilihat pada tabel 10 .

TABEL 10. TABel Hasil PeMbobotan Matriks

\begin{tabular}{|c|c|c|c|c|c|c|}
\hline $\begin{array}{c}\text { Alter } \\
\text { natif }\end{array}$ & $\begin{array}{c}\text { Inisial } \\
\text { Nama }\end{array}$ & $\begin{array}{c}\text { Masa } \\
\text { Kerja } \\
\text { (C1) }\end{array}$ & $\begin{array}{c}\text { Fung } \\
\text { sional } \\
\text { (C2) }\end{array}$ & $\begin{array}{c}\text { Kompe } \\
\text { tensi } \\
\text { (C3) }\end{array}$ & $\begin{array}{c}\text { Pendi } \\
\text { dikan } \\
\text { (C4) }\end{array}$ & $\begin{array}{c}\text { Tugas } \\
\text { Belajar } \\
\text { (C5) }\end{array}$ \\
\hline \multicolumn{2}{|c|}{ Bobot } & 0,20 & 0,15 & 0,35 & 0,20 & 0,10 \\
\hline A0 & - & 0,0119 & 0,0115 & 0,0206 & 0,0130 & 0,0080 \\
\hline A1 & AF & 0,0071 & 0,0029 & 0,0206 & 0,0087 & 0,0040 \\
\hline A2 & AM & 0,0048 & 0,0029 & 0,0206 & 0,0087 & 0,0040 \\
\hline A3 & AFB & 0,0119 & 0,0087 & 0,0206 & 0,0087 & 0,0040 \\
\hline A4 & AP & 0,0095 & 0,0058 & 0,0206 & 0,0087 & 0,0040 \\
\hline A5 & AH & 0,0095 & 0,0115 & 0,0206 & 0,0130 & 0,0040 \\
\hline A6 & DN & 0,0119 & 0,0115 & 0,0206 & 0,0130 & 0,0040 \\
\hline A7 & AC & 0,0119 & 0,0087 & 0,0041 & 0,0130 & 0,0040 \\
\hline A8 & ELF & 0,0119 & 0,0058 & 0,0041 & 0,0087 & 0,0040 \\
\hline A9 & ER & 0,0071 & 0,0058 & 0,0206 & 0,0087 & 0,0040 \\
\hline A10 & FS & 0,0071 & 0,0087 & 0,0206 & 0,0087 & 0,0040 \\
\hline A11 & FR & 0,0095 & 0,0058 & 0,0206 & 0,0087 & 0,0080 \\
\hline A12 & SM & 0,0095 & 0,0058 & 0,0041 & 0,0087 & 0,0040 \\
\hline A13 & IM & 0,0119 & 0,0087 & 0,0041 & 0,0087 & 0,0040 \\
\hline A14 & JP & 0,0095 & 0,0087 & 0,0206 & 0,0087 & 0,0040 \\
\hline A15 & JH & 0,0095 & 0,0087 & 0,0041 & 0,0087 & 0,0040 \\
\hline
\end{tabular}

p-ISSN 2301-7988, e-ISSN 2581-0588

DOI : 10.32736/sisfokom.v10i3.1240, Copyright @2020

Submitted : August 24, 2021; Revised : November 12, 2021; Accepted : November 15, 2021; Published : November 29, 2021 
terhadap alternatif 0 (A0). Berikut adalah hasil dari perhitungan utility degree dapat dilihat pada tabel 12 .

TABEL 12. TABel Hasil UtILITY DegReE (KI)

\begin{tabular}{|c|c|c|c|}
\hline Alternatif & Inisial Nama & $\mathbf{K i}$ & Ranking \\
\hline $\mathrm{A} 0$ & - & 1,0000 & - \\
\hline $\mathrm{A} 1$ & $\mathrm{AF}$ & 0,6656 & 14 \\
\hline $\mathrm{A} 2$ & $\mathrm{AM}$ & 0,6290 & 16 \\
\hline A3 & AFB & 0,8274 & 4 \\
\hline A4 & AP & 0,7465 & 10 \\
\hline A5 & $\mathrm{AH}$ & 0,9019 & 2 \\
\hline A6 & DN & 0,9385 & 1 \\
\hline A7 & $\mathrm{AC}$ & 0,6411 & 15 \\
\hline A8 & ELF & 0,5300 & 19 \\
\hline A9 & ER & 0,7099 & 12 \\
\hline $\mathrm{A} 10$ & FS & 0,7542 & 9 \\
\hline A11 & FR & 0,8079 & 5 \\
\hline A12 & SM & 0,4934 & 20 \\
\hline A13 & IM & 0,5743 & 17 \\
\hline A14 & JP & 0,7908 & 6 \\
\hline A15 & JH & 0,5377 & 18 \\
\hline A16 & $\mathrm{KE}$ & 0,7831 & 7 \\
\hline A17 & MS & 0,7270 & 11 \\
\hline A18 & MI & 0,7714 & 8 \\
\hline A19 & PS & 0,8351 & 3 \\
\hline $\mathrm{A} 20$ & RI & 0,7021 & 13 \\
\hline
\end{tabular}

Maka diperoleh hasil keputusan berdasarkan perhitungan di atas. Dimana nilai dari masing-masing alternatif diurutkan dari nilai yang tertinggi ke nilai terendah, seperti pada tabel 13 .

TABEL 13. TABEL Hasil KePUTUSAN

\begin{tabular}{|c|c|c|c|c|}
\hline Alternatif & $\begin{array}{r}\text { Inisial } \\
\text { Nama }\end{array}$ & Ki & Ranking & Keputusan \\
\hline A6 & DN & 0,9385 & 1 & Prioritas 1 \\
\hline A5 & AH & 0,9019 & 2 & Prioritas 2 \\
\hline A19 & PS & 0,8351 & 3 & Prioritas 3 \\
\hline A3 & AFB & 0,8274 & 4 & Prioritas 4 \\
\hline A11 & FR & 0,8079 & 5 & Prioritas 5 \\
\hline A14 & JP & 0,7908 & 6 & Prioritas 6 \\
\hline A16 & KE & 0,7831 & 7 & Prioritas 7 \\
\hline A18 & MI & 0,7714 & 8 & Prioritas 8 \\
\hline
\end{tabular}

\begin{tabular}{|c|c|c|c|c|}
\hline A10 & FS & 0,7542 & 9 & Prioritas 9 \\
\hline A4 & AP & 0,7465 & 10 & Prioritas 10 \\
\hline A17 & MS & 0,727 & 11 & Prioritas 11 \\
\hline A9 & ER & 0,7099 & 12 & Prioritas 12 \\
\hline A20 & R1 & 0,7021 & 13 & Prioritas 13 \\
\hline A1 & AF & 0,6656 & 14 & Prioritas 14 \\
\hline A7 & AC & 0,6411 & 15 & Prioritas 15 \\
\hline A2 & AM & 0,629 & 16 & Prioritas 16 \\
\hline A13 & IM & 0,5743 & 17 & Prioritas 17 \\
\hline A15 & JH & 0,5377 & 18 & Prioritas 18 \\
\hline A8 & ELF & 0,53 & 19 & Prioritas 19 \\
\hline A12 & SM & 0,4934 & 20 & Prioritas 20 \\
\hline
\end{tabular}

Dari hasil perhitungan tabel 13 maka alternatif dengan Ki tertinggi 0,9385 yaitu A6.

\section{Penerapan Metode COPRAS}

Langkah-langkah yang dilakukan dalam pengolahan data pada metode COPRAS :

1. Membuat Matriks Keputusan.

Berikut adalah hasil dari matriks keputusan dapat dilihat pada tabel 14 .

TABEL 14. TABEL MATRIKS KEPUTUSAN

\begin{tabular}{|c|c|c|c|c|c|c|}
\hline $\begin{array}{c}\text { Alter } \\
\text { natif }\end{array}$ & $\begin{array}{c}\text { Inisial } \\
\text { Nama }\end{array}$ & $\begin{array}{c}\text { Masa } \\
\text { Kerja } \\
\text { (C1) } \\
\text { Max }\end{array}$ & $\begin{array}{c}\text { Fung } \\
\text { sional } \\
\text { (C2) } \\
\text { Max }\end{array}$ & $\begin{array}{c}\text { Kompe } \\
\text { tensi } \\
\text { (C3) } \\
\text { Max }\end{array}$ & $\begin{array}{c}\text { Pendi } \\
\text { dikan } \\
\text { (C4) } \\
\text { Max }\end{array}$ & $\begin{array}{c}\text { Tugas } \\
\text { Belajar } \\
\text { (C5) } \\
\text { Min }\end{array}$ \\
\hline A1 & AF & 3 & 1 & 5 & 2 & 2 \\
\hline A2 & AM & 2 & 1 & 5 & 2 & 2 \\
\hline A3 & AFB & 5 & 3 & 5 & 2 & 2 \\
\hline A4 & AP & 4 & 2 & 5 & 2 & 2 \\
\hline A5 & AH & 4 & 4 & 5 & 3 & 2 \\
\hline A6 & DN & 5 & 4 & 5 & 3 & 2 \\
\hline A7 & AC & 5 & 3 & 1 & 3 & 2 \\
\hline A8 & ELF & 5 & 2 & 1 & 2 & 2 \\
\hline A9 & ER & 3 & 2 & 5 & 2 & 2 \\
\hline A10 & FS & 3 & 3 & 5 & 2 & 2 \\
\hline A11 & FR & 4 & 2 & 5 & 2 & 1 \\
\hline A12 & SM & 4 & 2 & 1 & 2 & 2 \\
\hline A13 & IM & 5 & 3 & 1 & 2 & 2 \\
\hline A14 & JP & 4 & 3 & 5 & 2 & 2 \\
\hline A15 & JH & 4 & 3 & 1 & 2 & 2 \\
\hline
\end{tabular}




\begin{tabular}{|c|c|c|c|c|c|c|}
\hline A16 & KE & 5 & 2 & 5 & 2 & 2 \\
\hline A17 & MS & 3 & 1 & 5 & 2 & 1 \\
\hline A18 & MI & 3 & 2 & 5 & 2 & 1 \\
\hline A19 & PS & 4 & 4 & 5 & 2 & 2 \\
\hline A20 & RI & 4 & 1 & 5 & 2 & 2 \\
\hline Jumlah & & 79 & 48 & 80 & 43 & 37 \\
\hline
\end{tabular}

2. Normalisasi Matriks

Matriks dinormalisasikan dengan membagi nilai dengan jumlah kolom dari kriteria. Berikut adalah hasil dari normalisasi matriks dapat dilihat pada tabel 15 .

TABEL 15. TABEL NORMALISASI MATRIKS

\begin{tabular}{|c|c|c|c|c|c|}
\hline $\begin{array}{c}\text { Alter } \\
\text { natif }\end{array}$ & $\begin{array}{c}\text { Masa } \\
\text { Kerja } \\
\text { (C1) }\end{array}$ & $\begin{array}{c}\text { Fung } \\
\text { sional } \\
\text { (C2) }\end{array}$ & $\begin{array}{c}\text { Kompe } \\
\text { tensi } \\
\text { (C3) }\end{array}$ & $\begin{array}{c}\text { Pendi } \\
\text { dikan } \\
\text { (C4) }\end{array}$ & $\begin{array}{c}\text { Tugas } \\
\text { Belajar } \\
\text { (C5) }\end{array}$ \\
\hline A1 & 0,0380 & 0,0208 & 0,0625 & 0,0465 & 0,0541 \\
\hline A2 & 0,0253 & 0,0208 & 0,0625 & 0,0465 & 0,0541 \\
\hline A3 & 0,0633 & 0,0625 & 0,0625 & 0,0465 & 0,0541 \\
\hline A4 & 0,0506 & 0,0417 & 0,0625 & 0,0465 & 0,0541 \\
\hline A5 & 0,0506 & 0,0833 & 0,0625 & 0,0698 & 0,0541 \\
\hline A6 & 0,0633 & 0,0833 & 0,0625 & 0,0698 & 0,0541 \\
\hline A7 & 0,0633 & 0,0625 & 0,0125 & 0,0698 & 0,0541 \\
\hline A8 & 0,0633 & 0,0417 & 0,0125 & 0,0465 & 0,0541 \\
\hline A9 & 0,0380 & 0,0417 & 0,0625 & 0,0465 & 0,0541 \\
\hline A10 & 0,0380 & 0,0625 & 0,0625 & 0,0465 & 0,0541 \\
\hline A11 & 0,0506 & 0,0417 & 0,0625 & 0,0465 & 0,0270 \\
\hline A12 & 0,0506 & 0,0417 & 0,0125 & 0,0465 & 0,0541 \\
\hline A13 & 0,0633 & 0,0625 & 0,0125 & 0,0465 & 0,0541 \\
\hline A14 & 0,0506 & 0,0625 & 0,0625 & 0,0465 & 0,0541 \\
\hline A15 & 0,0506 & 0,0625 & 0,0125 & 0,0465 & 0,0541 \\
\hline A16 & 0,0633 & 0,0417 & 0,0625 & 0,0465 & 0,0541 \\
\hline A17 & 0,0380 & 0,0208 & 0,0625 & 0,0465 & 0,0270 \\
\hline A18 & 0,0380 & 0,0417 & 0,0625 & 0,0465 & 0,0270 \\
\hline A19 & 0,0506 & 0,0833 & 0,0625 & 0,0465 & 0,0541 \\
\hline A20 & 0,0506 & 0,0208 & 0,0625 & 0,0465 & 0,0541 \\
\hline
\end{tabular}

3. Menentukan matriks keputusan berbobot yang ternormalisasi.

Menentukan bobot ternomalisasi dilakukan dengan cara mengalikan elemen matrik keputusan ternormalisasi dengan elemen bobot kriteria. Berikut adalah hasil dari pembobotan matriks dapat dilihat pada tabel 16 .

TABEL 16. TABEL BOBOT TERNORMALISASI

\begin{tabular}{|c|c|c|c|c|c|}
\hline $\begin{array}{c}\text { Alter } \\
\text { natif }\end{array}$ & $\begin{array}{c}\text { Masa } \\
\text { Kerja } \\
\text { (C1) }\end{array}$ & $\begin{array}{c}\text { Fung } \\
\text { sional } \\
\text { (C2) }\end{array}$ & $\begin{array}{c}\text { Kompe } \\
\text { tensi } \\
\text { (C3) }\end{array}$ & $\begin{array}{c}\text { Pendi } \\
\text { dikan } \\
\text { (C4) }\end{array}$ & $\begin{array}{c}\text { Tugas } \\
\text { Belajar } \\
\text { (C5) }\end{array}$ \\
\hline A1 & 0,0076 & 0,0031 & 0,0219 & 0,0093 & 0,0054 \\
\hline A2 & 0,0051 & 0,0031 & 0,0219 & 0,0093 & 0,0054 \\
\hline A3 & 0,0127 & 0,0094 & 0,0219 & 0,0093 & 0,0054 \\
\hline A4 & 0,0101 & 0,0063 & 0,0219 & 0,0093 & 0,0054 \\
\hline A5 & 0,0101 & 0,0125 & 0,0219 & 0,0140 & 0,0054 \\
\hline A6 & 0,0127 & 0,0125 & 0,0219 & 0,0140 & 0,0054 \\
\hline A7 & 0,0127 & 0,0094 & 0,0044 & 0,0140 & 0,0054 \\
\hline A8 & 0,0127 & 0,0063 & 0,0044 & 0,0093 & 0,0054 \\
\hline A9 & 0,0076 & 0,0063 & 0,0219 & 0,0093 & 0,0054 \\
\hline A10 & 0,0076 & 0,0094 & 0,0219 & 0,0093 & 0,0054 \\
\hline A11 & 0,0101 & 0,0063 & 0,0219 & 0,0093 & 0,0027 \\
\hline A12 & 0,0101 & 0,0063 & 0,0044 & 0,0093 & 0,0054 \\
\hline A13 & 0,0127 & 0,0094 & 0,0044 & 0,0093 & 0,0054 \\
\hline A14 & 0,0101 & 0,0094 & 0,0219 & 0,0093 & 0,0054 \\
\hline A15 & 0,0101 & 0,0094 & 0,0044 & 0,0093 & 0,0054 \\
\hline A16 & 0,0127 & 0,0063 & 0,0219 & 0,0093 & 0,0054 \\
\hline A17 & 0,0076 & 0,0031 & 0,0219 & 0,0093 & 0,0027 \\
\hline A18 & 0,0076 & 0,0063 & 0,0219 & 0,0093 & 0,0027 \\
\hline A19 & 0,0101 & 0,0125 & 0,0219 & 0,0093 & 0,0054 \\
\hline 0,0101 & 0,0031 & 0,0219 & 0,0093 & 0,0054 \\
\hline
\end{tabular}

4. Perhitungan memaksimalkan dan meminimalkan indeks untuk masing-masing alternatif.

Perhitungan memaksimalkan $\mathrm{S}+\mathrm{i}(\mathrm{C} 1+\mathrm{C} 2+\mathrm{C} 3+\mathrm{C} 4)$. Berikut adalah hasil memaksimalkan indeks untuk masing-masing alternatif dapat dilihat pada tabel 17 .

TABEL 17. TABEL HASIL MEMAKSIMALKAN INDEKS (S+I)

\begin{tabular}{|c|c|c|c|c|c|}
\hline $\begin{array}{c}\text { Alter } \\
\text { natif }\end{array}$ & $\begin{array}{c}\text { Masa } \\
\text { Kerja } \\
\text { (C1) }\end{array}$ & $\begin{array}{c}\text { Fung } \\
\text { sional } \\
\text { (C2) }\end{array}$ & $\begin{array}{c}\text { Kompe } \\
\text { tensi } \\
\text { (C3) }\end{array}$ & $\begin{array}{c}\text { Pendi } \\
\text { dikan } \\
(\mathbf{C 4})\end{array}$ & Nilai S+i \\
\hline A1 & 0,0076 & 0,0031 & 0,0219 & 0,0093 & 0,0476 \\
\hline A2 & 0,0051 & 0,0031 & 0,0219 & 0,0093 & 0,0450 \\
\hline A3 & 0,0127 & 0,0094 & 0,0219 & 0,0093 & 0,0589 \\
\hline A4 & 0,0101 & 0,0063 & 0,0219 & 0,0093 & 0,0532 \\
\hline A5 & 0,0101 & 0,0125 & 0,0219 & 0,0140 & 0,0641 \\
\hline A6 & 0,0127 & 0,0125 & 0,0219 & 0,0140 & 0,0667 \\
\hline A7 & 0,0127 & 0,0094 & 0,0044 & 0,0140 & 0,0460 \\
\hline
\end{tabular}

p-ISSN 2301-7988, e-ISSN 2581-0588

DOI : 10.32736/sisfokom.v10i3.1240, Copyright @ 2020

Submitted : August 24, 2021; Revised : November 12, 2021; Accepted : November 15, 2021; Published : November 29, 2021 


\begin{tabular}{|c|c|c|c|c|r|}
\hline A8 & 0,0127 & 0,0063 & 0,0044 & 0,0093 & 0,0383 \\
\hline A9 & 0,0076 & 0,0063 & 0,0219 & 0,0093 & 0,0507 \\
\hline A10 & 0,0076 & 0,0094 & 0,0219 & 0,0093 & 0,0538 \\
\hline A11 & 0,0101 & 0,0063 & 0,0219 & 0,0093 & 0,0487 \\
\hline A12 & 0,0101 & 0,0063 & 0,0044 & 0,0093 & 0,0357 \\
\hline A13 & 0,0127 & 0,0094 & 0,0044 & 0,0093 & 0,0414 \\
\hline A14 & 0,0101 & 0,0094 & 0,0219 & 0,0093 & 0,0564 \\
\hline A15 & 0,0101 & 0,0094 & 0,0044 & 0,0093 & 0,0389 \\
\hline A16 & 0,0127 & 0,0063 & 0,0219 & 0,0093 & 0,0558 \\
\hline A17 & 0,0076 & 0,0031 & 0,0219 & 0,0093 & 0,0430 \\
\hline A18 & 0,0076 & 0,0063 & 0,0219 & 0,0093 & 0,0462 \\
\hline A19 & 0,0101 & 0,0125 & 0,0219 & 0,0093 & 0,0595 \\
\hline A20 & 0,0101 & 0,0031 & 0,0219 & 0,0093 & 0,0501 \\
\hline Jumlah & & & & & 0,9 \\
\hline
\end{tabular}

\begin{tabular}{|c|c|c|}
\hline A20 & 0,0054 & 0,0054 \\
\hline Jumlah & & 0,0999 \\
\hline
\end{tabular}

6. Perhitungan bobot relatif tiap alternatif

Berikut adalah hasil perhitungan bobot relatif tiap alternatif dapat dilihat pada tabel 19.

TABEL 19. TABEL HASIL BOBOT RELATIF

5. Perhitungan Meminimalkan S-i (C5).

Berikut adalah hasil meminimalkan indeks untuk masingmasing alternatif dapat dilihat pada tabel 18 .

TABEL 18. TABEL HASIL MEMINIMALKAN INDEKS (S-I)

\begin{tabular}{|c|c|c|}
\hline Alternatif & Tugas Belajar (C5) & Nilai S-i \\
\hline $\mathrm{A} 1$ & 0,0054 & 0,0054 \\
\hline A2 & 0,0054 & 0,0054 \\
\hline A3 & 0,0054 & 0,0054 \\
\hline A4 & 0,0054 & 0,0054 \\
\hline A5 & 0,0054 & 0,0054 \\
\hline A6 & 0,0054 & 0,0054 \\
\hline A7 & 0,0054 & 0,0054 \\
\hline A8 & 0,0054 & 0,0054 \\
\hline A9 & 0,0054 & 0,0054 \\
\hline A10 & 0,0054 & 0,0054 \\
\hline A11 & 0,0027 & 0,0027 \\
\hline A12 & 0,0054 & 0,0054 \\
\hline A13 & 0,0054 & 0,0054 \\
\hline A14 & 0,0054 & 0,0054 \\
\hline A15 & 0,0054 & 0,0054 \\
\hline A16 & 0,0054 & 0,0054 \\
\hline A17 & 0,0027 & 0,0027 \\
\hline A18 & 0,0027 & 0,0027 \\
\hline A19 & 0,0054 & 0,0054 \\
\hline
\end{tabular}

\begin{tabular}{|c|c|c|}
\hline Alternatif & 1/S-i & $\mathrm{S}-\mathrm{i} *$ total dari $1 / \mathrm{S}-\mathrm{i}$ \\
\hline A1 & 185,1852 & 23 \\
\hline A2 & 185,1852 & 23 \\
\hline A3 & 185,1852 & 23 \\
\hline A4 & 185,1852 & 23 \\
\hline A5 & 185,1852 & 23 \\
\hline A6 & 185,1852 & 23 \\
\hline A7 & 185,1852 & 23 \\
\hline A8 & 185,1852 & 23 \\
\hline A9 & 185,1852 & 23 \\
\hline A10 & 185,1852 & 23 \\
\hline A11 & 370,3704 & 11,5 \\
\hline A12 & 185,1852 & 23 \\
\hline A13 & 185,1852 & 23 \\
\hline A14 & 185,1852 & 23 \\
\hline A15 & 185,1852 & 23 \\
\hline A16 & 185,1852 & 23 \\
\hline A17 & 370,3704 & 11,5 \\
\hline A18 & 370,3704 & 11,5 \\
\hline A19 & 185,1852 & 23 \\
\hline A20 & 185,1852 & 23 \\
\hline Jumlah & 4259,2593 & 425,5 \\
\hline
\end{tabular}

7. Tentukan urutan prioritas alternatif (Qi)

Berikut adalah hasil urutan prioritas alternatif dapat dilihat pada tabel 20.

TABEL 20. TABel Hasil PRioritas Alternatif (QI)

\begin{tabular}{|c|c|}
\hline Alternatif & $\mathbf{Q} \mathbf{i}=[($ Total S- $) /(\mathbf{S}-+$ total dari $\mathbf{1} / \mathbf{S}-\mathbf{i})]+(\mathbf{S}+)$ \\
\hline A1 & 0,0419 \\
\hline A2 & 0,0394 \\
\hline A3 & 0,0532 \\
\hline A4 & 0,0476 \\
\hline A5 & 0,0585 \\
\hline
\end{tabular}

p-ISSN 2301-7988, e-ISSN 2581-0588

DOI : 10.32736/sisfokom.v10i3.1240, Copyright (C2020

Submitted : August 24, 2021; Revised : November 12, 2021; Accepted : November 15, 2021; Published : November 29,2021 


\begin{tabular}{|c|c|}
\hline A6 & 0,0610 \\
\hline A7 & 0,0404 \\
\hline A8 & 0,0326 \\
\hline A9 & 0,0450 \\
\hline A10 & 0,0481 \\
\hline A11 & 0,0476 \\
\hline A12 & 0,0301 \\
\hline A13 & 0,0357 \\
\hline A14 & 0,0507 \\
\hline A15 & 0,0332 \\
\hline A16 & 0,0501 \\
\hline A17 & 0,0419 \\
\hline A18 & 0,0450 \\
\hline A19 & 0,0538 \\
\hline A20 & 0,0444 \\
\hline Jumlah & 0,9 \\
\hline
\end{tabular}

\begin{tabular}{|c|c|c|}
\hline A18 & 0,0450 & 73,8231 \\
\hline A19 & 0,0538 & 88,2223 \\
\hline A20 & 0,0444 & 72,8501 \\
\hline Qi Max & 0,0610 & \\
\hline
\end{tabular}

Hasil akhir dari perhitungan dengan menerapkan metode COPRAS, dapat dilihat pada tabel 22.

TABEL 22. TABEL HASIL PERANGKINGAN

\begin{tabular}{|c|c|c|c|}
\hline Alternatif & Ui & Ranking & Keputusan \\
\hline A6 & 100 & 1 & Prioritas 1 \\
\hline A5 & 95,8489 & 2 & Prioritas 2 \\
\hline A19 & 88,2223 & 3 & Prioritas 3 \\
\hline A3 & 87,2494 & 4 & Prioritas 4 \\
\hline A 14 & 83,0983 & 5 & Prioritas 5 \\
\hline A 16 & 82,1253 & 6 & Prioritas 6 \\
\hline A 10 & 78,9471 & 7 & Prioritas 7 \\
\hline A4 & 77,9742 & 8 & Prioritas 8 \\
\hline A11 & 77,9742 & 9 & Prioritas 9 \\
\hline A9 & 73,8231 & 10 & Prioritas 10 \\
\hline A 18 & 73,8231 & 11 & Prioritas 11 \\
\hline A20 & 72,8501 & 12 & Prioritas 12 \\
\hline A1 & 68,7375 & 13 & Prioritas 13 \\
\hline A 17 & 68,699 & 14 & Prioritas 14 \\
\hline A7 & 66,1812 & 15 & Prioritas 15 \\
\hline A2 & 64,5479 & 16 & Prioritas 16 \\
\hline A 13 & 58,5546 & 17 & Prioritas 17 \\
\hline A 15 & 54,4035 & 18 & Prioritas 18 \\
\hline A8 & 53,4306 & 19 & Prioritas 19 \\
\hline A12 & 49,2794 & 20 & Prioritas 20 \\
\hline
\end{tabular}

Dari hasil perhitungan tabel 22 maka alternatif dengan Ui tertinggi 100 yaitu A6.

\section{Penerapan Metode WASPAS}

Langkah-langkah yang dilakukan dalam pengolahan data pada metode WASPAS :

1. Membuat Matriks Keputusan

Berikut adalah hasil dari matriks keputusan dapat dilihat pada tabel 23 .

TABEL 23. TABEL MATRIKS KEPUTUSAN 


\begin{tabular}{|c|c|c|c|c|c|c|}
\hline $\begin{array}{c}\text { Alter } \\
\text { natif }\end{array}$ & $\begin{array}{c}\text { Inisial } \\
\text { Nama }\end{array}$ & $\begin{array}{c}\text { Masa } \\
\text { Kerja } \\
\text { (C1) }\end{array}$ & $\begin{array}{c}\text { Fung } \\
\text { sional } \\
\text { (C2) }\end{array}$ & $\begin{array}{c}\text { Kompe } \\
\text { tensi } \\
\text { (C3) }\end{array}$ & $\begin{array}{c}\text { Pendi } \\
\text { dikan } \\
\text { (C4) }\end{array}$ & $\begin{array}{c}\text { Tugas } \\
\text { Belajar } \\
\text { (C5) }\end{array}$ \\
\hline A1 & AF & 3 & 1 & 5 & 2 & 2 \\
\hline A2 & AM & 2 & 1 & 5 & 2 & 2 \\
\hline A3 & AFB & 5 & 3 & 5 & 2 & 2 \\
\hline A4 & AP & 4 & 2 & 5 & 2 & 2 \\
\hline A5 & AH & 4 & 4 & 5 & 3 & 2 \\
\hline A6 & DN & 5 & 4 & 5 & 3 & 2 \\
\hline A7 & AC & 5 & 3 & 1 & 3 & 2 \\
\hline A8 & ELF & 5 & 2 & 1 & 2 & 2 \\
\hline A9 & ER & 3 & 2 & 5 & 2 & 2 \\
\hline A10 & FS & 3 & 3 & 5 & 2 & 2 \\
\hline A11 & FR & 4 & 2 & 5 & 2 & 1 \\
\hline A12 & SM & 4 & 2 & 1 & 2 & 2 \\
\hline A13 & IM & 5 & 3 & 1 & 2 & 2 \\
\hline A14 & JP & 4 & 3 & 5 & 2 & 2 \\
\hline A15 & JH & 4 & 3 & 1 & 2 & 2 \\
\hline A16 & KE & 5 & 2 & 5 & 2 & 2 \\
\hline A17 & MS & 3 & 1 & 5 & 2 & 1 \\
\hline A18 & MI & 3 & 2 & 5 & 2 & 1 \\
\hline A19 & PS & 4 & 4 & 5 & 2 & 2 \\
\hline A20 & RI & 4 & 1 & 5 & 2 & 2 \\
\hline Jumlah & & 79 & 48 & 80 & 43 & 37 \\
\hline Max (Benefit) & 5 & 4 & 5 & 3 & - \\
\hline Min (Cost) & - & - & - & - & 1 \\
\hline Bobot & & 0,2 & 0,15 & 0,35 & 0,2 \\
\hline & & & & & & \\
\hline
\end{tabular}

\begin{tabular}{|c|c|c|c|c|c|c|}
\hline A7 & AC & 1,0000 & 0,7500 & 0,2000 & 1,0000 & 0,5000 \\
\hline A8 & ELF & 1,0000 & 0,5000 & 0,2000 & 0,6667 & 0,5000 \\
\hline A9 & ERF & 0,6000 & 0,5000 & 1,0000 & 0,6667 & 0,5000 \\
\hline A10 & FS & 0,6000 & 0,7500 & 1,0000 & 0,6667 & 0,5000 \\
\hline A11 & FR & 0,8000 & 0,5000 & 1,0000 & 0,6667 & 1,0000 \\
\hline A12 & SM & 0,8000 & 0,5000 & 0,2000 & 0,6667 & 0,5000 \\
\hline A13 & IM & 1,0000 & 0,7500 & 0,2000 & 0,6667 & 0,5000 \\
\hline A14 & JP & 0,8000 & 0,7500 & 1,0000 & 0,6667 & 0,5000 \\
\hline A15 & JH & 0,8000 & 0,7500 & 0,2000 & 0,6667 & 0,5000 \\
\hline A16 & KE & 1,0000 & 0,5000 & 1,0000 & 0,6667 & 0,5000 \\
\hline A17 & MS & 0,6000 & 0,2500 & 1,0000 & 0,6667 & 1,0000 \\
\hline A18 & MI & 0,6000 & 0,5000 & 1,0000 & 0,6667 & 1,0000 \\
\hline A19 & PS & 0,8000 & 1,0000 & 1,0000 & 0,6667 & 0,5000 \\
\hline A20 & RI & 0,8000 & 0,2500 & 1,0000 & 0,6667 & 0,5000 \\
\hline
\end{tabular}

\section{Menghitung Nilai Preferensi (Qi).}

Perhitungan nilai preferensi (Qi) dengan menggunakan persamaan 20. Berikut adalah hasil dari nilai preferensi (Qi) dapat dilihat pada tabel 25.

TABEL 25. TABEL NILAI PREFERENSI (QI)

\begin{tabular}{|c|c|c|c|c|c|c|}
\hline $\begin{array}{c}\text { Alter } \\
\text { natif }\end{array}$ & $\begin{array}{c}\text { Masa } \\
\text { Kerja } \\
\text { (C1) }\end{array}$ & $\begin{array}{c}\text { Fung } \\
\text { sional } \\
\text { (C2) }\end{array}$ & $\begin{array}{c}\text { Kompe } \\
\text { tensi } \\
\text { (C3) }\end{array}$ & $\begin{array}{c}\text { Pendi } \\
\text { dikan } \\
\text { (C4) }\end{array}$ & $\begin{array}{c}\text { Tugas } \\
\text { Belajar } \\
\text { (C5) }\end{array}$ & $\begin{array}{c}\text { Nilai } \\
\text { Qi }\end{array}$ \\
\hline A1 & 0,1200 & 0,0375 & 0,3500 & 0,1333 & 0,0500 & 0,5032 \\
\hline A2 & 0,0800 & 0,0375 & 0,3500 & 0,1333 & 0,0500 & 0,4709 \\
\hline A3 & 0,2000 & 0,1125 & 0,3500 & 0,1333 & 0,0500 & 0,6289 \\
\hline A4 & 0,1600 & 0,0750 & 0,3500 & 0,1333 & 0,0500 & 0,5696 \\
\hline A5 & 0,1600 & 0,1500 & 0,3500 & 0,2000 & 0,0500 & 0,6781 \\
\hline A6 & 0,2000 & 0,1500 & 0,3500 & 0,2000 & 0,0500 & 0,7083 \\
\hline A7 & 0,2000 & 0,1125 & 0,0700 & 0,2000 & 0,0500 & 0,4434 \\
\hline A8 & 0,2000 & 0,0750 & 0,0700 & 0,1333 & 0,0500 & 0,3745 \\
\hline A9 & 0,1200 & 0,0750 & 0,3500 & 0,1333 & 0,0500 & 0,5392 \\
\hline A10 & 0,1200 & 0,1125 & 0,3500 & 0,1333 & 0,0500 & 0,5689 \\
\hline A11 & 0,1600 & 0,0750 & 0,3500 & 0,1333 & 0,1000 & 0,6079 \\
\hline A12 & 0,1600 & 0,0750 & 0,0700 & 0,1333 & 0,0500 & 0,3497 \\
\hline A13 & 0,2000 & 0,1125 & 0,0700 & 0,1333 & 0,0500 & 0,4002 \\
\hline A14 & 0,1600 & 0,1125 & 0,3500 & 0,1333 & 0,0500 & 0,5999 \\
\hline A15 & 0,1600 & 0,1125 & 0,0700 & 0,1333 & 0,0500 & 0,3751 \\
\hline A16 & 0,2000 & 0,0750 & 0,3500 & 0,1333 & 0,0500 & 0,5980 \\
\hline A17 & 0,1200 & 0,0375 & 0,3500 & 0,1333 & 0,1000 & 0,5395 \\
\hline A18 & 0,1200 & 0,0750 & 0,3500 & 0,1333 & 0,1000 & 0,5768 \\
\hline
\end{tabular}

2. Normalisasi Matriks

Perhitungan matriks dinormalisasikan dengan menggunakan persamaan 17 dan 18. Berikut adalah hasil dari normalisasi matriks dapat dilihat pada tabel 24.

TABEL 24. TABEL NORMALISASI MATRIKS

\begin{tabular}{|c|c|c|c|c|c|c|}
\hline $\begin{array}{c}\text { Alter } \\
\text { natif }\end{array}$ & $\begin{array}{c}\text { Inisial } \\
\text { Nama }\end{array}$ & $\begin{array}{c}\text { Masa } \\
\text { Kerja } \\
\text { (C1) }\end{array}$ & $\begin{array}{c}\text { Fung } \\
\text { sional } \\
\text { (C2) }\end{array}$ & $\begin{array}{c}\text { Kompe } \\
\text { tensi } \\
(\mathbf{C 3})\end{array}$ & $\begin{array}{c}\text { Pendi } \\
\text { dikan } \\
\text { (C4) }\end{array}$ & $\begin{array}{c}\text { Tugas } \\
\text { Belajar } \\
\text { (C5) }\end{array}$ \\
\hline A1 & AF & 0,6000 & 0,2500 & 1,0000 & 0,6667 & 0,5000 \\
\hline A2 & AM & 0,4000 & 0,2500 & 1,0000 & 0,6667 & 0,5000 \\
\hline A3 & AFB & 1,0000 & 0,7500 & 1,0000 & 0,6667 & 0,5000 \\
\hline A4 & AP & 0,8000 & 0,5000 & 1,0000 & 0,6667 & 0,5000 \\
\hline A5 & AH & 0,8000 & 1,0000 & 1,0000 & 1,0000 & 0,5000 \\
\hline A6 & DN & 1,0000 & 1,0000 & 1,0000 & 1,0000 & 0,5000 \\
\hline
\end{tabular}




\begin{tabular}{|c|c|c|c|c|c|c|}
\hline A19 & 0,1600 & 0,1500 & 0,3500 & 0,1333 & 0,0500 & 0,6274 \\
\hline A20 & 0,1600 & 0,0375 & 0,3500 & 0,1333 & 0,0500 & 0,5325 \\
\hline
\end{tabular}

Maka dari hasil perhitungan tingkatan peringkat tertinggi dari alternatif. Dimana nilai dari masing-masing diurutkan dari nilai yang tertinggi ke nilai terendah, dapat dilihat pada tabel 26.

TABEL 26. TABEL HASIL PERANGKINGAN

\begin{tabular}{|c|c|c|c|}
\hline Alternatif & Nilai Preferensi & Ranking & Keputusan \\
\hline A6 & 0,7083 & 1 & Prioritas 1 \\
\hline$\overline{\mathrm{A} 5}$ & 0,6781 & 2 & Prioritas 2 \\
\hline$\overline{\mathrm{A} 3}$ & 0,6289 & 3 & Prioritas 3 \\
\hline A19 & 0,6274 & 4 & Prioritas 4 \\
\hline A11 & 0,6079 & 5 & Prioritas 5 \\
\hline A14 & 0,5999 & 6 & Prioritas 6 \\
\hline A16 & 0,598 & 7 & Prioritas 7 \\
\hline A18 & 0,5768 & 8 & Prioritas 8 \\
\hline A4 & 0,5696 & 9 & Prioritas 9 \\
\hline A10 & 0,5689 & 10 & Prioritas 10 \\
\hline A17 & 0,5395 & 11 & Prioritas 11 \\
\hline A9 & 0,5392 & 12 & Prioritas 12 \\
\hline A20 & 0,5325 & 13 & Prioritas 13 \\
\hline A1 & 0,5032 & 14 & Prioritas 14 \\
\hline A2 & 0,4709 & 15 & Prioritas 15 \\
\hline A7 & 0,4434 & 16 & Prioritas 16 \\
\hline A13 & 0,4002 & 17 & Prioritas 17 \\
\hline A15 & 0,3751 & 18 & Prioritas 18 \\
\hline A8 & 0,3745 & 19 & Prioritas 19 \\
\hline A12 & 0,3497 & 20 & Prioritas 20 \\
\hline
\end{tabular}

Dari hasil perhitungan dengan menerapkan metode WASPAS, dapat dilihat pada tabel 26 bahwa A6 memiliki nilai prioritas terbaik untuk direkomendasi sebagai dosen penguji skripsi dengan nilai preferensi tertinggi: 0,7083 .

\section{E. Perbandingan Hasil Metode ARAS, COPRAS dan WASPAS}

Perbandingan metode ARAS, COPRAS dan WASPAS dari hasil analisa perhitungan berdasarkan tabel 26, ditampilkan pada tabel 27 berikut.

TABEL 27. TABEl Hasil PERBANDINGan METODE

\begin{tabular}{|c|c|c|c|}
\hline ARAS & COPRAS & WASPAS & Ranking \\
\hline $\mathrm{A} 6=0,9385$ & $\mathrm{~A} 6=100$ & A6 $6=0,7083$ & 1 \\
\hline A5 $=0,9019$ & A5 $=95,8489$ & $\mathrm{~A} 5=0,6781$ & 2 \\
\hline $\mathrm{A} 19=0,8351$ & $\mathrm{~A} 19=88,2223$ & $\mathrm{~A} 3=0,6289$ & 3 \\
\hline A3 $=0,8274$ & $\mathrm{~A} 3=87,2494$ & $\mathrm{~A} 19=0,6274$ & 4 \\
\hline $\mathrm{A} 11=0,8079$ & A14 $=83,0983$ & $\mathrm{~A} 11=0,6079$ & 5 \\
\hline A14 $=0,7908$ & $\mathrm{~A} 16=82,1253$ & A14 $=0,5999$ & 6 \\
\hline $\mathrm{A} 16=0,7831$ & $\mathrm{~A} 10=78,9471$ & A16 $=0,598$ & 7 \\
\hline $\mathrm{A} 18=0,7714$ & $\mathrm{~A} 4=77,9742$ & $\mathrm{~A} 18=0,5768$ & 8 \\
\hline $\mathrm{A} 10=0,7542$ & A $11=77,9742$ & $\mathrm{~A} 4=0,5696$ & 9 \\
\hline $\mathrm{A} 4=0,7465$ & $\mathrm{~A} 9=73,8231$ & $\mathrm{~A} 10=0,5689$ & 10 \\
\hline $\mathrm{A} 17=0,727$ & $\mathrm{~A} 18=73,8231$ & $\mathrm{~A} 17=0,5395$ & 11 \\
\hline A9 $=0,7099$ & A $20=72,8501$ & $\mathrm{~A} 9=0,5392$ & 12 \\
\hline $\mathrm{A} 20=0,7021$ & $\mathrm{~A} 1=68,7375$ & A20 $=0,5325$ & 13 \\
\hline $\mathrm{A} 1=0,6656$ & $\mathrm{~A} 17=68,699$ & $\mathrm{~A} 1=0,5032$ & 14 \\
\hline $\mathrm{A} 7=0,6411$ & $\mathrm{~A} 7=66,1812$ & $\mathrm{~A} 2=0,4709$ & 15 \\
\hline $\mathrm{A} 2=0,629$ & $\mathrm{~A} 2=64,5479$ & $\mathrm{~A} 7=0,4434$ & 16 \\
\hline A $13=0,5743$ & $\mathrm{~A} 13=58,5546$ & A13 $=0,4002$ & 17 \\
\hline A $15=0,5377$ & A $15=54,4035$ & A $15=0,3751$ & 18 \\
\hline $\mathrm{A} 8=0,53$ & $\mathrm{~A} 8=53,4306$ & $\mathrm{~A} 8=0,3745$ & 19 \\
\hline A12 $=0,4934$ & A $12=49,2794$ & A12 $=0,3497$ & 20 \\
\hline
\end{tabular}

Dari tabel 27 dapat diketahui bahwa metode ARAS, COPRAS dan WASPAS menghasilkan pilihan yang sama untuk peringkat terbaik (A6) dan (A5).

\section{KESIMPULAN}

Pada penelitian ini digunakan tiga metode yaitu ARAS, COPRAS dan WASPAS untuk pemilihan dosen penguji skripsi. Ketiga metode ini adalah bagian dari Multi Criteria Decision Making (MCDM), yaitu metode pengambilan keputusan untuk menetapkan alternatif terbaik dari sejumlah alternatif berdasarkan beberapa kriteria tertentu. Sampel data yang digunakan berjumlah 20 data dengan 5 kriteria agar lebih mudah diimplementasikan. Metode ARAS menggunakan nilai utilitas (Ki) tertinggi untuk mendapatkan pilihan terbaik. Metode COPRAS didasarkan pada skor penilaian utilitas quantitatif (Ui) tertinggi untuk mendapatkan pilihan terbaik dari semua alternatif. Metode WASPAS menggunakan nilai preferensi $(\mathrm{Q})$ tertinggi untuk mendapatkan pilihan terbaik. Metode ARAS menghasilkan alternatif 6 (A6) dengan nilai peringkat (Ki) sebesar 0,9385 sebagai alternatif yang terbaik. Metode COPRAS menghasilkan alternatif 6 (A6) dengan utilitas quantitatif (Ui) sebesar 100 sebagai alternatif terbaik. Metode WASPAS menghasilkan alternatif 6 (A6) dengan nilai preferensi (Q) sebesar 0,7083 sebagai alternatif yang terbaik. 
Metode ARAS, COPRAS dan WASPAS terdapat beberapa kesamaan peringkat nilai prioritas pada peringkat $1,2,17,18$, 19 dan 20 sesuai dengan perhitungan yang telah dilakukan berdasarkan hasil perangkingan terlihat pada tabel 27. Pada dasarnya, ketiga metode tersebut dapat digunakan untuk pengambilan keputusan pemilihan dosen penguji skripsi berdasarkan kriteria dan bobot yang diinginkan. Metode ARAS, COPRAS dan WASPAS dapat digunakan untuk pengambilan keputusan dalam pemilihan dosen penguji skripsi. Dengan adanya penelitian ini diharapkan ke depannya konsep sistem pendukung keputusan berkelompok yang menggabungkan metode ARAS, COPRAS dan WASPAS bisa diterapkan ke dalam berbagai masalah pengambilan keputusan, sehingga bisa mendapatkan hasil keputusan yang lebih optimal.

\section{REFERENCES}

[1] I. Septiana, M. Irfan, A. R. Atmadja, and B. Subaeki, "Sistem Pendukung Keputusan Penentu Dosen Penguji Dan Pembimbing Tugas Akhir Menggunakan Fuzzy Multiple Attribute Decision Making dengan Simple Additive Weighting (Studi Kasus: Jurusan Teknik Informatika UIN SGD Bandung)," J. Online Inform., vol. 1, no. 1, p. 43, 2016. https://doi.org/10.15575/join.v1i1.10.

[2] K. B. Utomo and A. Rizal, "Penguji Tugas Akhir Dengan Menggunakan Metode Analytical Hierarchy Process ( AHP )," Just Ti, vol. 8, no. 1, pp. 979-986, 2016.

[3] R. R. A. Siregar, F. A. Sinaga, and R. Arianto, "Aplikasi Penentuan Dosen Penguji Skripsi Menggunakan Metode TF-IDF dan Vector Space Model," Comput. J. Comput. Sci. Inf. Syst., vol. 1, no. 2, p. 171, 2017.

[4] F. Pristiwati and A. Tomi, "Sistem Pendukung Keputusan dengan Metode WASPAS, COPRAS, dan EDAS : Menentukan Judul Skripsi,” vol. 4, p. 56, 2020. https://doi.org/10.30865/mib.v4i4.2431.

[5] V. Amalia, D. Syamsuar, and L. Atika, "Komparasi Metode WP SAW dan WASPAS Dalam Penentuan Penerima Beasiswa Penelusuran Minat dan Kemampuan," J. Inform., vol. 6, no. 1, pp. 114-121, 2019.

http://ejournal.bsi.ac.id/ejurnal/index.php/ji/article/vie w/5511.

[6] A. Jayant, S. Singh, and S. K. Garg, "An integrated approach with MOORA, SWARA, and WASPAS methods for selection of 3PLSP," Proc. Int. Conf. Ind. Eng. Oper. Manag., vol. 2018, no. JUL, pp. 2497-2509, 2018.

[7] A. Mardani et al., "A systematic review and metaAnalysis of SWARA and WASPAS methods: Theory and applications with recent fuzzy developments," Appl. Soft Comput. J., vol. 57, pp. 265-292, 2017. https://doi.org/10.1016/j.asoc.2017.03.045.

[8] D. Karabasevic, D. Stanujkic, and S. Urosevic, "The
MCDM Model for Personnel Selection Based on SWARA and ARAS Methods," Manag. - J. theory Pract. Manag., vol. 20, no. 77, pp. 43-52, 2015. DOI: 10.7595/management.fon.2015.0029

[9] K. A. Alam, R. Ahmed, F. S. Butt, S.-G. Kim, and K.M. Ko, "An Uncertainty-aware Integrated Fuzzy AHPWASPAS Model to Evaluate Public Cloud Computing Services," Procedia Computer Science, vol. 130, pp. 504-509, 2018, doi: 10.1016/j.procs.2018.04.068.

[10] Özbek, A., \& Erol, E., "Ranking of Factoring Companies in Accordance with ARAS and COPRAS Methods," International Journal of Academic Research in Accounting, Finance and Management Sciences, vol. 7(2), pp. 105-116. 2017.

[11] E. Turanoglu Bekar, M. Cakmakci, and C. Kahraman, "Fuzzy COPRAS method for performance measurement in total productive maintenance: a comparative analysis," Journal of Business Economics and Management, vol. 17, no. 5, pp. 663-684, 2016.

[12] Z. Turskis, N. Goranin, A. Nurusheva, and S. Boranbayev, "A fuzzy WASPAS-based approach to determine critical information infrastructures of EU sustainable development," Sustain., vol. 11, no. 2, 2019. doi: 10.3390/su11020424.

[13] R. P. Setyono and R. Sarno, "Comparative Method of Moora and Copras Based on Weighting of the Best Worst Method in Supplier Selection at ABC Mining Companies in Indonesia," 2019 International Conference on Information and Communications Technology (ICOIACT), Yogyakarta, Indonesia, 2019, pp. 354-359, doi: 10.1109/ICOIACT46704.2019.8938520.

[14] A. Mardani, M. K. Saraji, A. R. Mishra, and P. Rani, “A novel extended approach under hesitant fuzzy sets to design a framework for assessing the key challenges of digital health interventions adoption during the COVID19 outbreak," Appl. Soft Comput. J., vol. 96, p. 106613, 2020. https://doi.org/10.1016/j.asoc.2020.106613.

[15] Anas, "Sistem Pendukung Keputusan Penilaian Desa Terbaik Menggunakan Additive Ratio Assesment (ARAS)," J. Sist. Inf. Dan Tek. Komput., vol. 4, no. 1, pp. 32-39, 2019.

[16] A. A. Suryani and D. Ernawati, "Pemilihan Mitra Kerja Pemanfaatan Limbah Jonjot Menggunakan Metode Aras (Additive Ratio Assessment) Di Perum Xyz," Juminten J. Manaj. Ind. dan Teknol., vol. 01, no. 04, pp. 37-48, 2020.

[17] Rostamzadeh, R. E., A., et all., “A Fuzzy Aras Method for Supply Chain Management Performance Measurement in SMEs under Uncertainty", 
Transformations in Business \& Economics, Vol. 16, No 2A (41A), pp.319-348. 2017.

[18] S. Koçak, A. Kazaz, and S. Ulubeyli, "Subcontractor selection with additive ratio assessment method," Journal of Construction Engineering, Management \& Innovation, vol. 1, no. 1, pp. 18-32, Mar. 2018.

[19] D. M. Midyanti, R. Hidyati, S. Bahri, and U. T. Pontianak, "Rumah Di Kota Pontianak," vol. 4, no. 2, pp. 119-124, 2019.

[20] S. K. Dirjen et al., "Terakreditasi SINTA Peringkat 2 Komparasi Metode ELECTRE, SMART dan ARAS Dalam Penentuan Prioritas RENAKSI Pasca Bencana Alam," Masa Berlaku Mulai, vol. 1, no. 3, pp. 109-116, 2017.

[21] H. Garg and R. Arora, "Algorithms Based on COPRAS and Aggregation Operators with New Information Measures for Possibility Intuitionistic Fuzzy Soft Decision-Making," Math. Probl. Eng., vol. 2020, 2020.

[22] Esra; and AyG̣egül, "Air Conditioner Selection Problem With Copras And Aras Methods," Manas J. Soc. Stud., vol. 5 , no. 2, 2016.

[23] H. Garg and Nancy, "Algorithms for possibility linguistic single-valued neutrosophic decision-making based on COPRAS and aggregation operators with new information measures," Measurement, vol. 138, pp. 278-290, 2019.

[24] X. Peng and J. Dai, "Hesitant fuzzy soft decision making methods based on WASPAS, MABAC and COPRAS with combined weights," Journal of Intelligent \& Fuzzy Systems, vol. 33, no. 2, pp. 1313-1325, 2017.

[25] Y. Zheng, Z. Xu, Y. He, and H. Liao, "Severity assessment of chronic obstructive pulmonary disease based on hesitant fuzzy linguistic COPRAS method," Applied Soft Computing, vol. 69, pp. 60-71, 2018.

[26] Mishra, A.R., Rani, P. \& Pardasani, K.R. Multiplecriteria decision-making for service quality selection based on Shapley COPRAS method under hesitant fuzzy sets. Granul. Comput. 4, 435-449 https://doi.org/10.1007/s41066-018-0103-8.
[27] G. Ginting, S. Alvita, Mesran, A. Karim, M. Syahrizal, and N. K. Daulay, "Penerapan Complex Proportional Assessment ( COPRAS ) Dalam Penentuan Kepolisian Sektor Terbaik," J. Sains Komput. Inform., vol. 4, no. 2, pp. 616-631, 2020.

[28] E. K. Zavadskas, R. Baušys, and M. Lazauskas, "Sustainable assessment of alternative sites for the construction of awaste incineration plant by applying WASPAS method with single-valued neutrosophic set," Sustain., vol. 7, no. 12, 2015.

[29] M. Mathew and S. Sahu, "Comparison of new multicriteria decision making methods for material handling equipment selection," Manag. Sci. Lett., vol. 8, no. 3, pp. 139-150, 2018.

[30] E. K. Zavadskas, D. Kalibatas, and D. Kalibatiene, "A multi-attribute assessment using WASPAS for choosing an optimal indoor environment," Arch. Civ. Mech. Eng., vol. 16, no. 1, pp. 76-85, 2016. doi: 10.1016/j.acme.2015.10.002.

[31] A. R. Mishra, P. Rani, K. R. Pardasani, and A. Mardani, "A novel hesitant fuzzy WASPAS method for assessment of green supplier problem based on exponential information measures," Journal of Cleaner Production, vol. 238, p. 117901, Nov. 2019, doi: 10.1016/j.jclepro.2019.117901.

[32] S. Gupta, U. Soni, and G. Kumar, "Green supplier selection using multi-criterion decision making under fuzzy environment: A case study in automotive industry," Computers \& Industrial Engineering, vol. 136, pp. 663-680, Oct. 2019, doi: 10.1016/j.cie.2019.07.038.

[33] Z. Turskis, N. Goranin, A. Nurusheva, and S. Boranbayev, "A Fuzzy WASPAS-Based Approach to Determine Critical Information Infrastructures of EU Sustainable Development," Sustainability, vol. 11, no. 2, p. 424, Jan. 2019, doi: 10.3390/su11020424.

[34] R. Sistem, "Jurnal Resti," vol. 1, no. 1, pp. 19-25, 2017. http://jurnal.iaii.or.id/index.php/RESTI/article/view/20 94. 